\title{
Escrituras diaspóricas y migrantes trasandinos en la crónica urbana argentina*
}

\author{
Betina Sandra Campuzano**
}

\begin{abstract}
Resumen
Nos interesa indagar diferentes formas y grados de migración en crónicas urbanas del sistema literario argentino, centrándonos en su genericidad y la construcción del referente. Por un lado, observamos las migraciones genéricas en escrituras urgentes que exceden el concepto canónico de literatura, instalando nuevos modos de leer. Por otro, nos enfocamos en la migración. Para ello, a partir del análisis del discurso y desde una mirada transdisciplinaria, abordamos las crónicas Si me querés, queréme transa, de Cristián Alarcón (2010) y Sangre salada, de Sebastián Hacher (2011). El resultado de este trabajo avanza en la reflexión acerca de los procesos migratorios que propone la crítica literaria latinoamericana, como las discusiones en torno al retorno del realismo. Las conclusiones permiten proponer la noción de escrituras diaspóricas para referirnos a esta variedad y gradación de migraciones de diferente índole en los textos que nos convocan.
\end{abstract}

Palabras clave: escrituras diaspóricas, sujeto trasandino, migraciones, crónica urbana.

\section{Diasporic writings and trans-Andean migrants in the urban chronicle of Argentina}

\begin{abstract}
The interest lies in studying different forms and degrees of migration in urban chronicles of the Argentinian literary system. In particular, this paper is focused on its genres and the construction of the topic. On the one hand, I want to observe the migration of genres in those urgent writings which exceed the canonical concept of literature, introducing new ways of readings. On the other hand, I will focus on the migration of people. In order to do that, and from the discourse analysis and an interdisciplinary view, I propose an approach to the chronicles Si me querés, queréme transa, by Cristián Alarcón (2010), and Sangre Salada, by Sebastián Hacher (2011). The present paper shows the advances in the reflection on migratory processes proposed by Latin American literary criticism, as well as in the discussions on the return of realism. The conclusions allow me to propose the notion of diasporic scriptures to refer to this variety and gradation of migrations of different nature in the texts that summon us.
\end{abstract}

Este trabajo forma parte de las investigaciones que atendieron a la convocatoria sobre "Crónica Actual" realizada por la revista Literatura y Lingüística en colaboración con el grupo de investigación de "Prensa y Literatura" de la Universidad Academia de Humanismo Cristiano.

** Argentina. Profesora en Letras. Universidad Nacional de Salta, Argentina. Profesora Adjunta, Universidad Nacional de Salta, Salta, Argentina. betinacampuzano@gmail.com 
Keywords: Diasporic scriptures, Trans-Andean subject, Migrations, Urban chronicle.

"El verdadero hogar era más bien la comunidad o el pueblo al que pertenecía y sus miembros constituían una familia unida. Es posible que por esta razón se estudie lo andino con más frecuencia en el marco local o regional, a pesar de que las mismas poblaciones se formaron, desde sus orígenes preincaicos, por el continuo desplazamiento de olas migratorias de zonas frías hacia valles templados y de que, además, tanto los viajeros como los forasteros aceleraran, con una dinámica impredecible, cambios sociales y prácticas culturales a lo largo y ancho del territorio de los Andes."

Julio Noriega Bernuy

\section{Presentación}

En el presente artículo ${ }^{1}$ pretendemos abordar diferentes estados de migración en algunas crónicas urbanas del sistema literario argentino a partir de la presencia del migrante trasandino en el conurbano bonaerense. Así, en Sangre Salada. Una feria en los márgenes (2011) ${ }^{2}$, de Sebastián Hacher, aparece la investigación del periodista que transita por más de tres años por La Salada, la feria más imponente de la economía informal en el continente latinoamericano, en la que se entretejen las luchas por el espacio, la clonación de las marcas de los productos, las coimas policiales y los "aprietes" mafiosos, los asesinatos sin sentido. Del mismo modo, en Si me querés, queréme transa ${ }^{3}$ (2010), de Cristián Alarcón, nos hallamos frente a la migración boliviana y peruana que se instala en Villa del Señor, nombre ficticio de un espacio del Gran Buenos Aires, donde conviven la religiosidad al Cristo moreno de Pachacamilla, la guerra del narcotráfico por el territorio y la sospecha de la presencia de los senderistas que, luego de su derrota en Perú, se reciclaron en

\footnotetext{
1 Hemos abordado la cuestión de la religiosidad andina, la lucha por el territorio, la violencia del narcotráfico y la noción de crónica migrante en el artículo "Narcotráfico, migración y religiosidad andina en Si me querés, quereme transa de Cristian Alarcón” (2018). Luego, hemos avanzado sobre estas mismas reflexiones añadiendo la cuestión de la presencia de Sendero Luminoso en la crónica como un "cuento de guerra" en "Pachamama, ekekos y Cristos morenos. Nuevos realismos, violencia urbana y religiosidad andina en una literatura argentina migrante" (2018). Este artículo avanza en las reflexiones de ambos textos a partir del ingreso de nuevas nociones como sujeto trasandino (Noriega Bernuy 2012) y cuento de guerra (Nofal 2012).

En adelante, SS.

En adelante, SMQQT.
} 
el espacio bonaerense. En estos casos, estamos ante crónicas que dan cuenta de escenarios que transcurren entre los años noventa y dos mil, cuando emergen los brutales efectos del neoliberalismo iniciado en la época menemista que profundizó las brechas en la distribución de la riqueza y sus consecuentes exclusiones.

A partir de las herramientas que prevé el análisis del discurso y las categorías del pensamiento crítico latinoamericano, nos interesa relevar en ambas crónicas, al menos, dos estados de migraciones o traslados: en lo discursivo, estamos frente a lo que aquí llamaremos escrituras diaspóricas para referirnos a aquellas producciones testimoniales que exigen lectores que puedan entrar y salir de categorías literarias, escrituras que se desplazan entre diversos registros, y que son urgentes y performativas. Si bien las lábiles fronteras del género crónica resultan uno de los rasgos propios del periodismo narrativo, consideramos que la propuesta de entenderlo en términos de escritura diaspórica o migrante puede significar un avance conceptual en relación con aquellas clasificaciones consensuadas que enfatizan el carácter híbrido del género, mismo que implica un nuevo producto compuesto por diferentes especies. De cierto modo, este tipo de clasificaciones del género se han cristalizado y obturan las reflexiones. En cambio, poner el acento sobre el carácter diaspórico significa avanzar hacia una concepción que atienda más bien a la condición fluctuante y mutante de una textualidad que puede desplazarse y vivir en diferentes mundos, ámbitos o disciplinas (Mariaca Iturri 2018; Campuzano 2018b).

Asimismo, significa atender a los fluidos y las negociaciones entre estos diferentes mundos: el literario, el etnográfico y el periodístico. De allí que la propuesta de escrituras diaspóricas contenga — pero también exceda - al periodismo narrativo, a la literatura y a las historias de vida de la etnografía, pues se trataría de tres ambientes o mundos por los que los textos — como si fueran anfibios - pueden desplazarse, entrando y saliendo de las categorías propias de estas disciplinas. Por ello también la noción que aquí proponemos y que pone el énfasis en el carácter migrante de los textos, al tiempo que cuestiona las clasificaciones genéricas y las resoluciones que hablan de un "género híbrido", se erige como deudora de algunas nociones del pensamiento crítico latinoamericano, desde las literaturas heterogéneas y el sujeto migrante de Antonio Cornejo Polar (2005), hasta las literaturas postautónomas de Josefina Ludmer (2010) y los estudios performáticos de Diana Taylor (2015). 
En lo referencial o temático, estas crónicas dan cuenta de un fenómeno invisibilizado dentro del sistema literario argentino: la presencia de los migrantes trasandinos que se han desplazado desde Bolivia y Perú hacia las urbes del Cono Sur llevando consigo sus prácticas religiosas, sus historias políticas recientes, sus economías informales y sus cosmovisiones andinas. Estos archipiélagos que se conforman en otras macro-regiones, además, nos invitan a leer de un modo continental el fenómeno de la migración andina - hasta ahora encapsulado dentro los estudios "regionalistas" —; fenómenos cuya tradición se remonta a los forasteros y viajeros que, desde Guaman Poma hasta José María Arguedas, se desplazan por sinnúmero de lugares. Migración y violencia son los dos grandes fenómenos que recorrerán nuestro tiempo, advertía Cornejo Polar ("Una heterogeneidad..." 1996) hace un par de décadas. Consideramos que, a través de estas escrituras migrantes que incluyen crónicas, testimonios y autobiografías, se evidencian las estructuras de sentimiento de este tiempo presente que están atravesadas justamente por las traslaciones y las violencias.

\section{Escrituras diaspóricas: migraciones genéricas, retorno del realismo y nuevos modos de leer}

Si bien SMQQT y SS se inscriben claramente dentro del género "crónica urbana" o de no ficción, consideramos que ambas producciones pueden incluirse dentro de aquellas escrituras que, desde la urgencia $-\mathrm{y}$ dando una vuelta de tuerca al realismo-, se escapan de un concepto canónico de literatura e instalan de esta forma otros modos de leer. Pensamos, por supuesto, en la noción de literaturas postautónomas con la que Josefina Ludmer, a partir de un corpus de narrativas argentinas contemporáneas inclasificables, como es el caso de Bolivia construcciones (2006) de Sergio Di Nucci, cuyo seudónimo es Bruno Morales (2010), está dando cuenta

\footnotetext{
4 La controversia en torno a Bolivia construcciones es ampliamente conocida: bajo el seudónimo de Bruno Morales, el periodista Santiago Di Nucci presenta su novela al Premio 2006 La NaciónSudamericana y lo gana. Declara entonces que donaría el premio a una asociación de migrantes bolivianos y la obra se publica con este mismo seudónimo en octubre del 2006. Un tiempo después, un lector joven envía una carta a La Nación señalando similitudes con la novela Nada de Carmen Laforet: aunque ambas narrativas desarrollan diferentes tramas, sí coinciden en varios fragmentos. El jurado entonces revoca el premio, pues lo considera un caso de plagio. Antes del escándalo se habían desarrollado múltiples lecturas alrededor de la novela de Di Nucci e, incluso, Ludmer había propuesto la noción de literaturas postautónomas. Luego del estallido, se sucede una serie de álgidos debates en torno a la cuestión del plagio y el intertexto: entre los defensores y detractores de Di Nucci, se encuentran Washigton Cucurto, Elsa Drucaroff, Susana Santos, Julio Zoppi, Leandro Sai, Cristina Fangmann, Daniel
} 
del fin de la era de la autonomía del arte. Estas son escrituras que no admiten "lecturas literarias", como tampoco les importa si son entendidas como "realidad" o "ficción". Al contrario, son escrituras que se instalan localmente y "fabrican" un presente y un territorio, esto es, una isla urbana. En palabras de Ludmer, la isla urbana "no es un microcosmos ni una metonimia ni reproduce la realidad [...] Es un instrumento conceptual; una fábrica de imágenes y enunciados territoriales, provisorios y ambivalentes" (137). Leer las "islas urbanas" requiere, entonces, "un aparato diferente del que usábamos antes", esto es, “otras palabras y categorías" para pensar la significación.

Estas escrituras atraviesan las fronteras de la literatura y son por ello ambivalentes y diaspóricas, pues entran y salen con soltura de los criterios o las categorías literarias, como lo son las nociones de autor, obra, estilo o texto. En este sentido, y como señala Sandra Contreras (2008) a propósito del abordaje a la narrativa de César Aira, estas escrituras pueden inscribirse en la problemática de un "retorno del realismo", cambian los modos de leer y son, evidentemente, escrituras performativas pues, antes que "conocer", pretenden "hacer" territorios ${ }^{5}$. Por su parte, Diana Taylor (2015) sugiere pensar la performance como un marco teórico, pero también metodológico, que nos permita observar el modo en que se transmite el conocimiento tanto por medio de la palabra como a través del cuerpo, de la cultura letrada como de la popular. Los migrantes, en este sentido, evidencian tales transmisiones de la memoria pues, al trasladarse de un espacio al otro, llevan consigo sus visiones de mundo, sus memorias, espacialidades y temporalidades impresas tanto en las palabras como en la corporeidad (Bueno Chávez 2004).

En otras palabras, Ludmer habla de "fabricar" territorios y presentes escapándose así de las categorías literarias con las que nos acercamos a la lectura y Contreras sostiene que estos nuevos realismos no pretenden

\footnotetext{
Link y Maximiliano Tomas. Más allá de todas estas posiciones, lo cierto es que la escritura de Di Nucci resulta una narrativa que ha logrado incomodar.

5 Dice Contreras a propósito: “... no se trata del realismo positivista, ingenuo, confiado en la transparencia del lenguaje, sino de un 'nuevo realismo' que representa tanto mejor la realidad, el presente, cuanto más crítica sea su intención cognoscitiva, cuanto mejor superen sus procedimientos la banalidad de una pretensión puramente mimética. Es la regla de los realismos del siglo XX, podríamos decir. En este contexto, yo creo que la gran vuelta que Aira le estaría dando a las 'vueltas sobre el realismo' de fin de siglo es que desplaza el vínculo creativo entre lo real y el artista: del conocimiento (del orden de la representación) a la acción (al orden de la performance). Este desplazamiento es decisivo, es sustancial — porque transforma la naturaleza del vínculo—, y al mismo tiempo difícil, muy difícil, de captar y definir. Tal vez haya que decir: la literatura de Aira no quiere conocer la realidad, quiere hacer realismo." (48). La cursiva corresponde al original.
} 
"representar" o "conocer" la realidad, sino "hacerla" con palabras. Hay allí, en el realismo reciente, un claro gesto performático que, agregará luego la crítica rosarina, está dando cuenta de una pulsión documental y de nuevos modos de leer. Por nuestra parte, si recordamos que Roger Chartier (1993), al estudiar la historia de la lectura y la de los libros en la Edad Moderna, explica que los modos de leer no son otra cosa que "formas de estar en la sociedad", posiciones desde donde se lee, consideramos posible sostener que las crónicas urbanas son dispositivos escriturarios performáticos, que se inscriben dentro de estos nuevos realismos, que desbordan conceptos y categorías literarias, que poseen una pulsión documental, que fabrican territorios y presentes, que obligan a salirnos de la noción clásica de literatura y leer de otro modo porque, justamente, estamos viviendo de otro modo y desde otras posiciones en otra coyuntura histórica. Con esto queremos decir que las crónicas urbanas, entonces, pueden escaparse de las estancas clasificaciones genéricas o de los sólidos estantes de la literatura, el periodismo, la etnografía o la no ficción, pero no porque sean "textos híbridos", como la crítica se ha encargado de definir al género, desde metáforas como la del ornitorrinco de la prosa propuesta por Juan Villoro, sino porque son ellas textualidades que se desplazan entre diferentes registros y modos de leer. En síntesis, a partir de las lecturas de Ludmer, Contreras, Taylor y Chartier, proponemos repensar las calificaciones clásicas de la crónica urbana que la consideran un "género híbrido" y proponer, más bien, concebirla como una escritura diaspórica que se traslada entre diversos registros y modos de leer, en esa urgencia que requiere el testimonio y la "fabricación" de un territorio y un presente con palabras.

Asimismo, en esta propuesta subyace otro concepto del que también es deudora: nos referimos a la noción de literaturas heterogéneas (1980) que Antonio Cornejo Polar elaboró a partir de la lectura del neoindigenismo en la producción de José María Arguedas, autor que resulta un ejemplo ineludible de las escrituras disruptivas del siglo XX (Elmore 2015), pues transita inconclusa entre diversos registros (el diario o escritura íntima, el diálogo mítico de los zorros, la novela de la migración serrana en Chimbote). Así, da cuenta de los cambios urbanos propios de una modernidad desigual, los procesos migratorios y las yuxtaposiciones culturales, capturados en una mirada que es etnográfica y poética a la vez. Cornejo Polar entiende que una literatura heterogénea implica la presencia de un elemento en la situación comunicativa que 
corresponde a un universo sociodiscursivo diferente del resto: por ejemplo, en el indigenismo el referente corresponde al mundo indígena, mientras productor y destinatario comparten el mismo universo criollo y occidental.

Luego, el crítico peruano, al avanzar sobre su propuesta, comprenderá que cada elemento de la situación comunicativa puede ser heterogéneo en sí mismo: el canal, el referente, el código, el productor y el receptor, por ejemplo. Así, el pensamiento cornejo-polariano propone la noción de sujeto heterogéneo y, especialmente la de sujeto migrante, para referirse a aquellos sujetos quebrados o escindidos por la experiencia de la migración, en los que habitan una o más temporalidades, memorias y posiciones. Sostenemos entonces que las crónicas urbanas pueden considerarse del mismo modo escrituras diaspóricas o migrantes, pues estaríamos ante una heterogeneidad en el orden discursivo: registros, memorias y voces diferentes se desplazan entre los discursos literario, etnográfico y periodístico. Estos, a su vez, coexisten en una textualidad y no diluyen sus diferencias en un tercer elemento híbrido. Luego, puede haber otras heterogeneidades por las que fluyen estas escrituras como pueden ser la temática o referencial (que repite de algún modo el gesto del indigenismo, pero ya no en el ámbito de la hacienda, sino en la urbe misma a partir de la migración) y la que refiere a la instancia de producción (que acerca la crónica urbana al testimonio canónico de corte etnográfico que conocemos a partir del Premio Casa de las Américas y que implica la presencia de una doble autoría solidaria compartida entre letrado e informante). De ellas, nos ocuparemos a continuación.

\section{Los cronistas migrantes: de la ajenidad del oficio al ayllu}

La crónica de Alarcón o la de Hacher pueden resultar discursivamente tan migrantes como el mismo mundo al que refieren, pues su escritura implica un proceso de investigación periodística en el que intervienen entrevistas a informantes andinos que migraron hacia el espacio bonaerense, vistas a expedientes judiciales originados en los países de procedencia y largas estancias en las comunidades de migrantes donde, entre comidas y religiosidades, suceden los hechos relatados. Así, lo podemos ver en SS cuando el cronista narra el proceso de las entrevistas: "Los encuentros con Eva fueron cerca de diez. Los días que tenía ganas de hablar, sus monólogos comenzaban en los recuerdos y terminaban con ella imaginando 
situaciones ideales" (Hacher 41). De algún modo, ello da cuenta de cómo el investigador desarrolla una mirada detallada y un claro propósito etnográfico a la hora de escribir; esto es, el "estar allí" que requiere la tarea del antropólogo y la descripción densa que propone Clifford Geertz (2000).

Pero el cronista también incorpora reflexiones ensayísticas y avanza, incluso, hacia metáforas culturales que se desprenden de su descripción etnográfica. Pensamos, por ejemplo, en el modo en que al describir los procesos de "imitación" o "clonación" de la ropa "falsificada" en la feria, sugiere una metáfora sobre la identidad misma del espacio, de los trabajadores y de los mismos migrantes que, luego de varias generaciones, ya no son falsificaciones, sino mutaciones:

La Salada funciona por contagio. La imitación se puede hacer a ojo, pero la forma más efectiva es comprar una pieza, desarmarla, hacer un molde y ponerse a producir. Si esa forma de copiar se multiplica y se hacen copias de copias, el resultado termina siendo una mutación: lo que se obtiene en una tercera o cuarta generación ya no es ropa falsificada, sino un híbrido que se aleja cada vez más del original y comienza a escribir su propia historia. (Hacher 117$)^{6}$

De igual manera lo advertimos cuando Alarcón describe su primera entrevista con Alcira, la transa (esto es, la dealer o pasadora de drogas, uno de los estamentos del negocio del narcotráfico) que es la protagonista de su investigación y de su relato en la Villa del Señor:

Alcira tiene el cuerpo de un mastín napolitano. Es gruesa, aunque no gorda; una masa de músculos concentrados en los brazos, la espalda y el cuello. La boca bien dibujada, los ojos achinados, los pómulos salidos de la cara redonda le dan cierta altivez. Se para derecho, firme, con los hombros hacia atrás. Mira de frente. Los ojos son de un negro profundo, pequeños, vitales. A la sonrisa suele ganarle un rictus de preocupación. La vi por primera vez en La Perla, el bar de Once. Llegué demasiado tarde y ella estaba sentada, vestida de pantalón y remera rosados, con un bebé de pocos meses en los brazos: su hija Martita. Tomaba un café con leche y parecía dispuesta a hablar. "A mí me va a hacer bien acor-

En adelante, el destacado es nuestro. 
darme de algunas cosas que tengo guardadas muy adentro mío", me dijo. En la primera conversación avanzó veloz y decidida, como lanzada por los rápidos de la memoria. Me impresionó su honestidad, la manera en que mencionó los hechos que cambiaron su vida. Cómo vio matar. Cómo mandó matar. (Alarcón 30)

El cronista describe con minucia a su informante, su silueta, las circunstancias y el escenario de la primera entrevista, al tiempo que matiza tal descripción con sus impresiones y evaluaciones, poniendo al descubierto su subjetividad. Y es que las escrituras diaspóricas pueden también inscribirse dentro del 'giro subjetivo' (2007) del que habla Beatriz Sarlo para referirse a la retórica testimonial, a la intensidad de la experiencia, al predominio de los sujetos y de las historias mínimas e íntimas. Consideramos entonces que, si bien hay un evidente trabajo investigativo periodístico y/o etnográfico, el grado de edición y novelización en las crónicas de Alarcón y Hacher resulta mayor a otras escrituras etnográficas canónicas. Hay en ellas, además, una evidente preocupación estética: “avanzó veloz y decidida, como lanzada por los rápidos de la memoria”, escoge Alarcón para describir la verborragia de su informante, o las metáforas que esboza Hacher en las que desplaza el sentido de la ropa imitada hacia la condición de la identidad migrante; por lo que no dudamos de que se trate de escrituras que se trasladan lábilmente entre los registros del periodismo, la etnografía y la literatura.

Además, en ambos casos se introduce un considerable número de reflexiones metatextuales en torno al género "crónica”, como también al rol del letrado o amanuense. El periodista se halla lejos de disimular sus intervenciones durante el proceso de edición, como sí sucede con los epígonos del testimonio canónico ${ }^{7}$, o de borrar las dificultades que posee el investigador, quien termina más bien empatizando e involucrándose con el mundo de los informantes. Por supuesto, nos referimos aquí a una de las consabidas problemáticas que responden al testimonio etnográfico, tal como lo conocemos desde las propuestas de Miguel Barnet/Esteban Montejo, Domitila Chungara/Moema

Con la noción de testimonio epigonal (Campuzano 2017) nos referimos a aquellos relatos de corte etnográfico en los que podemos ver cristalizadas las variables del testimonio hispanoamericano canonizado con el Premio Casa de las Américas. Entre esas variables, hallamos la solidaridad entre letrado e informante, el principio de verosimilitud, los pasajes de la oralidad a la escritura, el disimulo del intelectual solidario que niega su tarea de mediación, por ejemplo. 
Viezzer y Rigoberta Menchú/Elizabeth Burgos Debray. Es decir, si recordamos la doble vertiente del testimonio de la que nos habla extensamente la crítica literaria fundacional del género desde los años noventa (Sklodowska 1992; Amar Sánchez 1992), que distingue entre los testimonios etnográficos y los periodísticos o de no ficción, la cuestión de la edición resulta una de las variables del género que aún hoy continúa apareciendo en los textos de carácter testimonial tanto de un corte como del otro. De allí que Sklodowska, por ejemplo, se detenga en los años noventa en el análisis de los prólogos y cómo en estos el letrado solidario, en términos de Achugar (1994), intenta "disimular" su intervención en el proceso de traducción y edición a fin de lograr la verosimilitud. Planteos similares realiza Amar Sánchez, a partir de la producción de Rodolfo Walsh y Elena Poniatowska, cuando se refiere al modo en que en las crónicas periodísticas no se trata de "prestar" la voz a quienes no la tienen, sino de cubrir con la de ellos los silencios, transformando el testimonio en casi un monólogo donde el silencio corresponde, más bien, al periodista (Amar Sánchez 63-64).

Así, la presencia de un letrado solidario que termina por empatizar e, incluso, constituirse como un actor más del ámbito de los informantes - en estos casos, los periodistas - y de esta manera ya no se preocupa por "disimular" su intervención pueden observarse tanto en SS como en SMQQT. Por ejemplo, así sucede cuando Hacher pone en evidencia el modo en que, en cierto momento, termina involucrándose - hasta incluso afectivamente ${ }^{8}$ - en el escenario de La Salada, del que inicialmente se sentía ajeno o del que solo le interesaba describir etnográficamente: "Yo como todos los demás, camino con lo mío a cuestas" (17), “A nosotros lo que nos interesa es la vida en la feria. Lo de las marcas nos da igual" (48), “Desde ese día nos sentimos parte de La Salada” (51).

El caso de Alarcón es aún más interesante en este aspecto. Será el episodio del pedido de padrinazgo que le realiza Alcira al cronista el que más dé cuenta de cómo el investigador, que primero intenta mantener la ética distancia con los informantes, termina involucrándose con el mundo trasandino y, de cierta forma, transformándose a partir de esta vinculación. Así, Alarcón recurre a la visita a una bruja: atendiendo a cómo esta influye en la creencia de Alcira, el cronista se vale de los 
vaticinios para evadir el pedido de padrinazgo y mantener así la distancia profesional:

Cubierta con una colcha amarilla, sobre ella comenzó su tarea. Pensé en la mai Oxún. Quiso comenzar con mi vida, con el devenir de mi propia vida. Le dije no, solo quiero saber sobre los personajes de la historia que estoy escribiendo. No le gustó la idea, pero procedió. Me dijo que al más poderoso de todos lo descubriría en una situación que jamás debía divulgar si no quería perder la vida. Si lo cuentas, te matan. [...] La visita a la bruja rindió sus frutos cuando regresé. Alcira se aferraba tanto a las creencias de las deidades paganas y hechizos andinos que el argumento de la bruja del caribe sobre lo de firmar juntos el mismo papel me resultó ideal para espantar la idea del padrinazgo. (130-131)

Si bien en varias ocasiones Alarcón se refiere a sí mismo como el "periodista" o el "escritor", es decir, lo hace desde su rol de investigador y productor del texto, esa función se transforma a lo largo del relato: su reticencia inicial se convierte en aceptación del padrinazgo. Este pasaje da cuenta de al menos dos transformaciones: primero, el cronista se involucra de tal modo en el mundo que investiga que adquiere una nueva posición, "desde adentro", la de un personaje o un actor más dentro de la saga narco. Luego, el padrinazgo forma parte de la composición andina; por eso, el cronista no solo adquiere responsabilidades y lazos con el hijo de Alcira sino que - podemos arriesgar - se convierte en miembro de su ayllu o comunidad, de su archipiélago andino o su familia, estableciendo así relaciones de reciprocidad y solidaridad. Recordemos que para la visión de mundo andino, la colectividad y la noción de yanantin —esto es, la relación, la complementariedad y la cooperación — rigen la vida en los Andes y la individualidad; chulla o wakcha está asociada, en cambio, a la desventura, la carencia y la esterilidad; de ahí que esté mal visto andar chulla, solo o sin ayllu (Mamani Macedo, "Yanantin..." 2019). Este mismo tipo de vinculaciones también forman parte del paisaje y la comunidad de los migrantes paraguayos retratados por Hacher:

Eva tenía seis años y no sabía por qué, pero la ausencia [del padre] no le dio tristeza. La madre se concentró en atender el almacén de techo de paja que regenteaba en las afueras de Asunción y en ayudar a los vecinos que se juntaban en su casa todas las tardes. Allí, mientras compartían un tereré helado, 
resolvían cómo ayudar a alguien que no tenía medios para ir al hospital, a una mujer que había enviudado o cuál era el mejor método para arreglar alguna calle del barrio. (31)

Entonces, la migración o el desplazamiento no solo sucede en el referente o el tema migratorio ni en la imbricación de discursos o en la relación entre periodista e informante, sino que también sucede en el cronista mismo, quien a través de la investigación "desde adentro" se incorpora al ayllu, a la Villa del Señor o a La Salada. Es decir, de algún modo, los cronistas empiezan a jugar un rol en esa guerra por el territorio - ya sea el del narcotráfico o el de la feria- pero también, y sobre todo, se involucran en estos espacios a partir de los lazos afectivos que establecen, de la incorporación de los modos de ver el mundo y de vincularse entre pares, de las relaciones de reciprocidad, colaboración y solidaridad, de los ayllus que se han trasladado junto con sus migrantes. Con esto queremos decir dos cosas: por una parte, episodios como el del pedido del padrinazgo o los modos de resolver las carestías de los vecinos nos permiten poner el acento en los vínculos solidarios entre los migrantes bolivianos, peruanos y paraguayos, y no solo atender a las situaciones de violencia urbana que, en el imaginario contemporáneo, pueden incluso ahondar en las estigmatizaciones. Por otra parte, estos ejemplos ponen en evidencia cómo los migrantes trasandinos resultan no solo sujetos heterogéneos, escindidos por la experiencia de la migración, sino también sujetos heterogeneizantes, en el sentido propuesto por Raúl Bueno Chávez, esto es, modifican los lugares de arribo con la incorporación de sus prácticas y cosmovisiones, generando nuevas heterogeneidades.

En resumen, las crónicas SMQQT y SS pueden considerarse escrituras migrantes, pues —más allá de sus referentes - se desplazan entre diversos registros y géneros, al tiempo que obligan a los cronistas a desplazarse también en sus posiciones: los investigadores, sean periodistas o etnógrafos, se trasladan desde relaciones de ajenidad hasta el involucrarse afectiva y culturalmente con los migrantes trasandinos. Son estos últimos quienes generan así nuevos estados de heterogeneidad y modifican el paisaje del lugar de arribo al incorporar sus prácticas, pero también sus afectos, sus modos de ver y organizar el mundo. 


\section{El archipiélago trasandino: la serpiente amaru que engulle al conurbano bonaerense}

Si atendemos especialmente al referente, repitiendo acaso el gesto de las literaturas indigenistas del siglo XX, podemos advertir otro estado de heterogeneidad que trasciende los paisajes de la sierra y la costa peruanas: nos referimos a la presencia del sujeto migrante trasandino que adquiere diferentes dimensiones en su traspaso al conurbano bonaerense. Si en el caso de SS el migrante boliviano toma posesión del territorio a través de las ferias de Urkupiña, Ocean y Punta Mogotes desatando así una guerra por el espacio, en SMQQT nos hallamos ante el cuento (Ludmer 1977; Nofal 2012) de cómo los senderistas, que fracasaron en la guerra popular prolongada, se reciclan en el negocio del narcotráfico en la Amazonía peruana, migran hacia Argentina por Bolivia llevando consigo su culto al Cristo de Pachacamilla, e inician una nueva - y diferente-guerra, ahora, por el dominio del territorio en las villas miserias bonaerenses. De esta forma, hallamos la matriz de un cuento, un fragmento o un rumor, que nunca sabremos si es verosímil o no, que enlaza la historia reciente argentina con la andina y la continental.

Estamos frente a un tipo de migración que excede el movimiento campo/ciudad o sierra/costa retratado en la literatura peruana o en la boliviana y que alude, más bien, a un desplazamiento trasandino (Noriega Bernuy 2012). Al abordar el caso del artista Fredy Roncalla radicado en Nueva Jersey, Noriega Bernuy propone hablar de un sujeto migrante trasandino para referirse a "los miles de indígenas quechuas y mestizos que, en diferentes países del mundo, viven formando el 'archipiélago andino' de comunidades trasplantadas geográficamente fuera de los Andes" (28). Noriega Bernuy sugiere que las comunidades andinas se desplazan hacia los nuevos lugares con sus hogares, sus ayllus, sus religiosidades y sus formas de vincularse, configurando así un archipiélago, término que el crítico peruano retoma a su vez de John Murra (Noriega Bernuy 28). En este sentido, recordemos además que durante los años setenta, ochenta y noventa se mantuvo un contingente de migrantes intralatinoamericanos, mientras en los dos mil esta cantidad aumentó modestamente, dejando de ser entonces transfronteriza. Así, llegaron los migrantes peruanos a Buenos Aires conformando, junto con los bolivianos, la colectividad andina más cuantiosa en el Cono Sur (Melella 2016). 
De esta manera, SS describe el modo en que las familias de migrantes bolivianos se han desplazado hacia el conurbano bonaerense para establecer las redes de la economía informal en la feria más grande del continente, que convive con las coimas policiales y con las extorsiones de otros grupos que se disputan el control del territorio. Al mismo tiempo, han trasplantado sus comidas, su música, sus cholitas luchadoras, los paisajes de La Paz, las relaciones entre compadres, como también el culto a la Virgen de Urkupiña, cuya imagen curiosamente coadyuva en la prosperidad de sus fieles:

A esa altura, Ingeniero Budge es un barrio deforme. Las calles parecen secuelas de un bombardeo y la iluminación pública no existe, pero muchas de las casas tienen dos o tres pisos y autos nuevos estacionados en la puerta. El contraste es producto de la feria. En los últimos años La Salada permitió un crecimiento desigual, a veces monstruoso, que desequilibró la arquitectura del barrio. (Hacher 16)

Cada lunes, unos quinientos inmigrantes se reunían al costado del Autopista Riccheri, en el Puente 12. Por la tarde se improvisaba una feria de comidas típicas, cerveza y algunos productos contrabandeados desde Bolivia y Brasil. [...] un grupo de cholitas lo rescató a fuerza de rasguñar y morder a los agentes. Edwin - al que todavía le faltaban veinte años para pesar 150 kilos y ser el buda de la abundancia- estaba allí para comprar Metisán, una crema boliviana que calma casi todos los dolores. (17)

Las mujeres no tenían miedo de lanzarse contra esos argentinos gigantes como si fueran las cholitas voladoras que pelean para el público en los clubes de La Paz. (40)

Otro tanto sucede en SMQQT: la comunidad peruana se ha trasladado también, con el fracaso de sus revoluciones devenidas en un cuento de pasados terrucos y un presente asociado con el narcotráfico, a una villa del conurbano bonaerense a la que ha modificado arquitectónicamente, engulléndola:

La geografía del barrio se volvió compleja. [...] El trazado de la calle depende de cómo avanzan las tomas de terrenos por nuevos desesperados que buscan un techo construyendo casillas de chapa y madera donde pueden, o por la intrincada logística 


\section{de los narcotraficantes peruanos que suelen disponer del es- pacio público como si fuera propio. (Alarcón 63)}

El archipiélago andino repite con esta traslación el gesto de la serpiente amaru que aprieta y engulle, en esta ocasión, ya no a la Lima criolla y "blanca" de la que hablaba Salazar Bondi en el consabido ensayo Lima la horrible (1964), sino más bien a la urbe argentina, rioplatense y europeizante. Además, es esta - la serpiente amaru — una metáfora muy potente propuesta por la escritura de José María Arguedas para referirse a los procesos migratorios de los pueblos serranos que arriban a la costa criolla en el marco de los procesos de la modernidad en América Latina. Las barriadas no solo son cinturones de miseria, sino que son también una especie de serpiente amaru que, lanzada por la voracidad del hambre, aprieta el cerco hasta engullirlo y aplasta a los hombres que viven en las zonas residenciales y que son los causantes de la inequidad (Bueno Chávez 71). Esta figura, además, puede explicarnos cómo el migrante, que está escindido y quebrado, evidencia estados de heterogeneidad; al mismo tiempo que también produce nuevas heterogeneidades en el lugar de arribo. El sujeto trasandino no solo es modificado por la experiencia migratoria, sino que él mismo también modifica la urbe: reestructura y andiniza su arquitectura y sus prácticas ${ }^{9}$.

Como señala el epígrafe con el que iniciamos este artículo, la crítica ha restringido los estudios de las migraciones andinas al ámbito de lo regional o, en el mejor de los casos, de la nación peruana, pero lo cierto es que la andinidad ha sido migrante desde los tiempos de la conquista y la colonia, siempre ha caminado el autor como sucede con Guaman Poma. Por eso, el abordaje a las crónicas de las migraciones andinas producidas en Argentina puede resultar un campo novedoso e interesante para los estudios migratorios. Junto con la narrativa periodística de Cristián Alarcón y de Sebastián Hacher, hallamos otras propuestas como Los

\footnotetext{
A propósito, pensamos en cómo Fredy Mamani propone reestructurar el paisaje de la Villa 31 en Buenos Aires a partir de la arquitectura del Alto en La Paz: "Para Mamani no se trata de excentricidades, sino de una arquitectura que transmite la identidad y recupera el orgullo de la cultura aymara, un pueblo originario que habita la meseta andina del lago Titicaca y cuya población se reparte entre el occidente de Bolivia, el sureste de Perú y el norte de Chile. Mamani, como la mayoría de sus clientes asentados en El Alto, es aymara. Su voluntad inicial - primero en sus estudios de ingeniero y luego en los de arquitecto, carrera de la que también se recibió- fue retomar la arquitectura de sus ancestros. 'En mis obras lo esencial es recuperar la iconografía y los trazos geométricos tallados en las ruinas de Tiwanaku', explica, mientras sus trabajos se proyectan en el escenario de la sala Jorge Luis Borges. 'No son una torta, como algunos dicen, sino que tienen un lenguaje. Yo fui a París y también vi otras tortas, pero no están de color', dice alargando la última $\mathrm{O}$ y provocando la risa del auditorio. 'Mis formas y colores tienen un sentido. Mis construcciones tienen una funcionalidad'”. (Etchenique 2019).
} 
otros... (2011) de Josefina Licitra que traza una cartografía de las periferias del conurbano bonaerense o las crónicas digitales de Gabriela Cabezón Cámara (2007) sobre los artistas bolivianos y su integración en Buenos Aires. Son todas estas propuestas modos de "fabricar" territorios, como propone Ludmer, a partir de la investigación periodística, la mirada etnográfica y la apuesta literaria. Resta relevar qué están escribiendo los mismos migrantes andinos en esta parte del Cono Sur, lo que puede ser objeto de otra investigación.

\section{La guerra por el territorio y el "cuento" de Sendero Luminoso}

Ahora bien, estos archipiélagos andinos se han desplazado con sus visiones de mundo y con sus ayllus, pero también con sus guerras y sus cuentos: mientras Hacher trata las disputas por el territorio en La Salada, Alarcón evidencia la batalla por el espacio que llevan a cabo los grupos narcos en el conurbano bonaerense. Hay, en ambos casos, un cuento de guerra (Nofal, "Escritura testimonial..." 2016) ${ }^{10}$ que se repite, esto es, una matriz de un relato más amplio que se reitera fragmentariamente como podemos verlo en los siguientes fragmentos:

Era la época del uno a uno, y nadie pensaba que se iba a disparar el dólar. A Jorge se le ocurrió hacer un relevamiento de lo que se había vendido y del dinero que entraba. Y resulta que faltaba una plata y se la había llevado uno de los administradores, Raúl Corrillo. Lo rajaron en seguida, pero empezó la guerra.

Según Charles, a partir de ese descubrimiento se formó un grupo de cincuenta feriantes que no querían pagar. Iban, armaban sus puestos y no aportaban nada. Llegaron a controlar cerca de trescientos puestos, el treinta por ciento de la feria.

-Era un infierno. Se juntaban entre diez y te tiraban un puesto por la cabeza. Nos daban con palos, con adoquines. Después iban a los tribunales de Lomas de Zamora y decían que acá los coaccionábamos, que éramos violentos. Si te muestro las fotos no vas a poder creer: esto era una guerra.

10 Rossana Nofal propone, a partir de su lectura de Ludmer, la noción de cuento de guerra para referirse a un mecanismo narrativo que construye la memoria colectiva a partir de la reiteración de una matriz. 
Charles narraba los hechos con una vaga indignación. No especulaba ni omitía datos, al menos no de forma consciente: era una historia vieja, de la que casi nadie en la feria se acordaba. (Hacher 61)

En SS la guerra entre grupos se desata por el dominio del territorio, el pago de coimas y la "seguridad" en la feria. El modo en que se conoce esta historia de enfrentamientos, que se remonta a los orígenes de la feria, sucede por medio del cuento, el rumor casi olvidado por las colectividades y la transmisión de la memoria a través de la figura de un cuentero, Charles, quien insiste en emplear el término "guerra" y toda la incomodidad que ello implica ${ }^{11}$. Nofal propone leer los testimonios en términos de "guerra", pues se trata de volver sobre los primeros relatos de los testigos y de los viejos militantes - los cuenteros - que hablaron de "guerra" para contar las historias heroicas. Frente a las fórmulas breves que se acercan más bien a la propaganda política o al eslogan (recordemos, por ejemplo, las ideas de la "guerra sucia" o la de "los dos demonios") de las que hablan los militantes de los DD.HH., Nofal propone volver sobre el género discursivo "parte de guerra" como aquel que es, en efecto, una escritura urgente que se adscribe a la tradición de la literatura de bandidos que propone Eric Hobsbawm (2011). La palabra "guerra" genera incomodidad y permite alejarse de identidades unitarias y compactas como sucede con los héroes y las víctimas, para abrir camino a los soldados, a los traidores, a los bandidos, a los militantes y a los desaparecidos, con todo el arco de complejidades que supone cada uno de estos actores. Hablar en términos de "guerra" no significaría, entonces, “descifrar las razones de la represión" sino "identificar una matriz presente en los relatos en donde cada elemento resuena, diseminado, en registros múltiples y sus opuestos” (Nofal, “Escritura testimonial...” 156).

En cuanto a SMQQT, el rumor de la presencia amenazadora de los senderistas en el conurbano bonaerense y el cuento de su mutación en narcotraficantes funciona a partir del conocimiento de que, en la última etapa de acción de Sendero Luminoso, la guerrilla llegó a la zona

\footnotetext{
11 La crítica argentina, además, señala la incomodidad que genera el empleo del término "guerra", pues este indica un enfrentamiento entre ejércitos y, por ende, este uso ha sido objeto de numerosos debates entre los militantes de diversas organizaciones y de los DD.HH en la Argentina. Sin embargo, Nofal va más allá de este speech y avanza sobre los sentidos del "parte de guerra" como una escritura urgente, por una parte y, por otra, sobre cómo el empleo de "guerra" nos remite a figuras no heroicas ni compactas, sino a las derrotas y las rendiciones de todo aquel que participa en una contienda. De allí que no le interesen los héroes, víctimas ni victimarios, sino los bandidos y los traidores, por ejemplo.
} 
amazónica donde entró en contacto con las redes de narcotráfico: había entre ambas organizaciones un interés económico mutuo. Lo que en un principio pretendió ser un medio que pudiera facilitar la provisión de dólares y de armas, se convirtió luego en un fin en sí mismo (Ezcárzaga, “Auge y caída..." 18). De allí, surge una inferencia: el traslado de los senderistas y narcotraficantes desde la Amazonía peruana hacia Buenos Aires, vía Bolivia. La religiosidad andina, el crimen del narcotráfico y la sombra del terror que desató Sendero Luminoso en tierras ayacuchanas se conjugan, como si fuera un western andino trastocado al espacio bonaerense, durante las ejecuciones que se suceden entre los bandos antagónicos:

Todos llevaban la cara tapada con un pasamontañas de lana negro. Como los terroristas. Dicen que el viejo Valdivia se sintió acorralado contra un paredón y cuando vio que le iban a caer, entonces dijo:

-Esperen, conchas de su madre. Quiero saber quién me va a matar. ¡Sáquense esa huevada de la cara!

De un solo escupitajo Jerry le voló el gorro de la visera. La sangre salpicó la campera de cuero negra. Le estalló la cabeza. Había sesos de Valdivia en la pared. Se veía en los flashazos de los disparos. Eso fue lo que quedó en la memoria de la gente; los pasamontañas, y esa forma de matar tan espectacular que no se había visto antes en Villa del Señor. Pasaron por el pasillo. Iban con las caras cubiertas, como en la guerra, como los de Sendero Luminoso, que llegaban en la noche y no dejaban títere con cabeza. (Alarcón 77)

En la cita vemos cómo los sicarios adoptan la guardarropía guerrillera (Nofal, "Configuraciones..." 2015) ${ }^{12}$ del terruco (el "pasamontañas negro"), cuya imagen "queda en la memoria de la gente”. Y esa máscara que adoptan los narcos en el territorio bonaerense será asociada con la brutalidad y la barbarie de los senderistas durante la guerra en el país

12 Rossana Nofal recupera la categoría de guardarropía de Ángel Rama y la reelabora atendiendo al abordaje del género testimonial y las políticas de la memoria. Propone hablar de una guardarropía revolucionaria para referirse al giro que se produce "desde la centralidad de la trama en los testimonios canónicos a la centralidad del personaje en las poéticas de la memoria" ("Configuraciones metafóricas..." 843). De esta manera, se interesa por abordar la legitimidad de la palabra en otras formas testimoniales diferentes a las historias de vida de la etnografía, a partir del relevamiento de ciertas metáforas referidas a estos vestuarios o disfraces. 
andino: "esa forma tan espectacular de matar", "llegaban en la noche", "no dejaban títere con cabeza". "Eso" que queda en la memoria de la gente es justamente el cuento, la matriz o el fragmento de un relato mayor: la historia de la cruenta guerra en el Perú, que es también el relato de las guerras en el continente. No hay en ella héroes ni víctimas, pero sí bandidos, traidores y rendidos que evidencian un sujeto escindido y quebrado por la experiencia de guerra.

La matriz que se reproduce aquí piensa en los guerrilleros como los terrucos que habitaron las zonas serrana y amazónica durante el conflicto armado peruano y que, ante el fracaso, devienen en narcotraficantes que se trasladan por los pasillos de la Villa del Señor. El empleo despectivo del término "terruco" devela un mirar oblicuo (Franconi, "O olhar oblíquo..." 2006), es decir, una mirada de soslayo sobre la alteridad que se construye a partir de presupuestos y prejuicios ${ }^{13}$. Se trata, más bien, de una sospecha, antes que una certeza o una constatación, sobre los migrantes peruanos que nunca dejan de ser criminalizados: si han sido guerrilleros en un pasado no muy lejano en la tierra andina, seguramente ahora son narcos en el nuevo espacio. Así lo podemos ver en el siguiente apartado:

[Niki Lauda] Era el único de los narcos de Villa del Señor a quien se acusaba con pruebas judiciales de ser exsoldado de Sendero Luminoso. Así lo confirmaba un fax de Interpol que llegó a la Dirección de Antiterrorismo de la Policía Federal. Aunque parecía más un mito que una verdad, durante seis meses investigué si era cierto, si era por lo menos verosímil que un miembro de la guerrilla maoísta se hubiera reciclado en matón narco. Sendero estaba en la Argentina. Varios de los líderes y cuadros intermedios se habían exiliado y muchos habían conseguido calidad de refugiados, con asistencia de la Iglesia y de la ONU. Niki Lauda fue el único de los narcos de Villa del Señor que llegó a Buenos Aires como un perseguido político. (Alarcón 2010, 144)

Expresiones del cronista tales como "Aunque parecía más un mito” e "investigué si era cierto, si era por lo menos verosímil" dan cuenta de

13 Rodolfo Franconi rastrea, a través de la noción de la mirada oblicua, la problemática confrontación del sujeto colonial con la alteridad que se constituye como tal en dicho enfrentamiento. Se trata de una mirada que no ve directamente, sino que presupone antes que averiguar (Bueno Chávez 2004). 
cómo esta posible presencia de los senderistas en la periferia bonaerense puede entenderse como un rumor, una versión o un fragmento de una historia mayor. Es decir, puede pensarse como el cuento de guerra del que habla Rossana Nofal para referirse a ese mecanismo narrativo que construye la memoria colectiva a partir de la reiteración de una matriz.

Esta noción - la de cuento de guerra - puede resultar provechosa si atendemos a cómo se reciclan los relatos previos del génesis y el desarrollo de la acción senderista en el Perú: "Para que exista un cuento tiene que haber con anterioridad algo que relatar y quizás, la disposición de 'dejarse engañar'; nada de lo que se relata puede ser efectivamente real" (Nofal, "Cuentos de guerra y soldados..." 133). El cuento de guerra, además, supone una retórica de héroes que fracasaron, tal como propone pensarlo la estudiosa tucumana. Esto se evidencia en la presencia de los senderistas que, ante la derrota, están rendidos y se reciclan por tanto como los narcotraficantes en el imaginario de la Villa del Señor:

Porque él, un hombre con su experiencia, alguien que pasó por Sendero Luminoso, que cosechó en la selva, que hizo todos los escalones de tráfico para consagrarse como buen mayorista, confiable, con todos esos tiros en el cuerpo y vivo, el que se salvó de aquel accidente en la cordillera, y de esa caída libre desde un segundo piso, no se iba a dejar atrapar jugando de sicario, o de soldado de su propio mando. Él era el jefe y, por eso, me explica, él no estuvo allí, sino bien resguardado a cuatro cuadras del lugar de los hechos. (Alarcón 289)

En el caso de SS, también hallamos una mirada oblicua que se construye, siempre bajo la sospecha y el prejuicio, en torno al migrante boliviano quien, desde la visión del argentino, siempre será criminalizado, será el enemigo que causa miedo y por tanto debe ser eliminado. Se configura así una "nueva" guerra por el territorio ensangrentado de La Salada:

—Mirá — decía él- son todos unos chorros. [...] — ¿Qué tendría que haber hecho yo? — se quejó Elías-. Tener una pistola y pegarle un tiro a cada uno.

Lo decía y blandía el dedo índice a un lado y a otro, acribillando a dos imaginarios rateros que huían con lo suyo. Elías era esa clase de persona que opina que la solución a todos los problemas es eliminar a quienes lo molestan y reordenar el 


\section{mundo a imagen y semejanza suya. (Hacher 119)}

Pensar, entonces, en términos de "guerra" estos enfrentamientos y disputas por el territorio - ya sea el de la feria más grande del Cono Sur o el que se disputan los grupos narco- como también observar el modo en que los vecinos se miran de soslayo avanzan sobre formas no compactas ni homogéneas de construir al referente - los migrantes trasandinosen estas crónicas. Es decir, estamos ante otras formas de heterogeneidad que se construyen en estas escrituras diaspóricas.

\section{A modo de conclusión}

En ambas crónicas, cuyo referente es el migrante trasandino, podemos observar que las comunidades bolivianas y peruanas se desplazan hacia el conurbano bonaerense conformando archipiélagos, reestructuran así la arquitectura, introducen sus cosmovisiones y modos de vincularse propios del mundo andino; por lo que entendemos que se tratan de sujetos heterogéneos y heterogeneizantes a la vez. Sin embargo, los migrantes son también objeto de miradas oblicuas y son los actores de los cuentos que siempre los tendrán bajo sospecha y, de esta manera, construirán "nuevas guerras", ahora, en el espacio de la villa en el Cono Sur. Por un lado, se trata de la violencia que se desata por el dominio del territorio entre las colectividades migrantes - ya sea en el escenario de La Salada a causa del "progreso" económico y las coimas policiales, o bien en la Villa del Señor a causa del narcotráfico-; pero, por otro, se trata también de una nueva "guerra" que es, en realidad, muy antigua y que criminaliza a la alteridad cuando construye sus representaciones. Quizás, se trata de una "nueva" vuelta de tuerca, no tan solo en lo que respecta a las escrituras diaspóricas y los nuevos realismos que "fabrican" islas urbanas, sino también al modo en que se exacerban en la contemporaneidad los nacionalismos latinoamericanos, que en los últimos tiempos han girado hacia los gobiernos de centro-derecha. Sin duda, las escrituras migrantes dan cuenta de los cambios culturales vaticinados en estas crónicas urbanas, que logran captar las estructuras de sentimiento (Williams 2009) que empiezan a esbozarse en los años dos mil y hallan su clímax en estos tiempos.

De esta manera, el abordaje de este corpus de crónicas argentinas, que se vincula con el sistema literario andino y continental, tiene como resultado el avance dentro de las reflexiones en torno al pensamiento cornejo-polariano de la heterogeneidad, a partir de nociones como las 
de escrituras diaspóricas y migrantes trasandinos que ponen el acento en el intercambio de flujos y en las traslaciones, como también en las identificaciones no compactas. Asimismo, permite pensar los avatares de estos tiempos, cómo las subjetividades y los estereotipos se han sedimentado desde la Colonia y la República, y cómo su matriz emerge nuevamente a través de miradas de soslayo, cuentos memoriosos y nuevas guerras por el territorio en el contexto de intensos procesos migratorios continentales.

\section{Referencias bibliográficas}

Achugar, Hugo. En otras palabras, otras historias. (Comp.). Montevideo, FHCE, Universidad de la República, 1994.

Alarcón, Cristian. Si me querés, quereme transa. Buenos Aires, Norma, 2010.

Amar Sánchez, Ana María. El relato de los hechos. Rodolfo Walsh: testimonio y escritura. Buenos Aires, Ediciones de la Flor, 2008 [1992].

Bueno Chávez, Raúl. Antonio Cornejo Polar y los avatares de la cultura latinoamericana. Lima, Universidad Mayor de San Marcos, 2004.

Cabezón Cámara, Gabriela. “Cultura boliviana en la Argentina: el duro camino de la integración”. Portal de la comunidad boliviana radicada en la Argentina, 21 de junio de 2007. Recuperado de http://www.comunidadboliviana.com.ar/shop/detallenot. asp?notid=862 . 15 de setiembre de 2019.

Campuzano, Betina. "Indios urbanos y tempestades andinas: del testimonio epigonal al relato de guerra en la narrativa peruana (2003-2015)". Cuadernos del Hipogrifo, no. 7, 2017, pp. 82-90. Recuperado de http://www.revistaelhipogrifo.com/?page $\mathrm{id}=1203.30$ de mayo de 2018.

"Narcotráfico, migración y religiosidad andina en Si me querés, quereme transa de Cristian Alarcón”. Oltreoceano, no. 14, 2018a, pp. 223-232. Recuperado de http://riviste.forumeditrice. it/oltreoceano/article/view/877. 10 de enero de 2019.

"Pachamama, ekekos y Cristos morenos. Nuevos realismos, violencia urbana y religiosidad andina en una literatura 
argentina migrante". Cuadernos del Hipogrifo, no. 10, 2018b, pp. 65-84. Recuperado de http://www.revistaelhipogrifo. com/.10 de enero de 2019.

_. “Trazar genealogías: memoria de género y cancionero latinoamericano en la crónica urbana de Pedro Lemebel". Textos Híbridos, vol. 6, 2018c, pp. 1-18.

Chartier, Roger. Libros, lecturas y lectores en la Edad Moderna. Madrid, Alianza, 1993.

Contreras, Sandra. En torno al realismo y otros ensayos. Rosario, Nube Negra, 2018.

Cornejo Polar, Antonio. "La profundidad histórica del indigenismo". Literatura y sociedad en el Perú. La novela indigenista. Lima, Lasontay, 2005 [1980].

"Una heterogeneidad no dialéctica: sujeto y discurso migrantes en el Perú moderno". Revista Iberoamericana, vol. 62, no. 176-177, Julio-Dic. 1996, pp. 837-844.

Elmor, Peter. "El zorro de arriba y el zorro de abajo es una de las experiencias extremas de la literatura latinoamericana”. Entrevista Gerardo Saravia y Patricia Wiesse. Revista IDEELE, no. 251, 2015. Recuperado de https://ojs.uv.es/index.php/ kamchatka/article/view/7603/7731. 01 de marzo de 2019.

Etchenique, María Belén. "Freddy Mamani, el arquitecto andino que quiere transformar con su estilo a la Villa 31". Clarín [Buenos Aire]. 26 de marzo de 2019.

Ezcárzaga, Fabiola. “Auge y caída de Sendero Luminoso”. Bajo el volcán. Revista de Posgrado de Sociología, no. 3, 2001, pp. 75-97.

Franconi, Rodolfo. "O olhar oblíquo: uma categoria cultural. Conceituação e exemplos”. RCLL, vol. 32, no. 63-64, 2006, pp. 105-115.

Geertz, Clifford. La interpretación de las culturas. Barcelona, Gedisa, 2000. Hacher, Sebastián. Sangre salada. Una feria en los márgenes. Buenos Aires, Marea, 2011.

Hobasbawm, Eric. Bandidos. Barcelona: Crítica, 2011.

Licitra, Josefina. Los otros. Una historia del conurbano bonaerense. Buenos Aires, Debate, 2011.

Ludmer, Josefina. “Contar el cuento”. Onetti. Los procesos de construcción del relato. Buenos Aires, Sudamericana, 1977, pp. 143-186. 
Aquí América Latina. Una especulación. Buenos Aires, Eterna Cadencia, 2010.

Mamani Macedo, Mauro. “Yanantin: relación, complementariedad y cooperación en el mundo andino". Estudios de Teoría Literaria. Revista Digital: Artes, Letras y Humanidades, vol. 8, no. 16, 2019, pp. 191-203.

Mariaca Iturri, Guillermo. "La crónica: teoría y política del siglo XXI". En: XIII Jornadas Andinas de Literatura Latinoamericana. Río Branco: Universidade Federal do Acre, Brasil, 2018. Inédito.

Melella, Cecilia. Migrantes de países andinos en la Argentina. Prensa gráfica, redes virtuales y construcción identitaria. Buenos Aires, Biblos, 2016.

Morales, Bruno. Grandeza boliviana. Buenos Aires, Eterna Cadencia, 2010.

Noriega Bernuy, Julio. Caminan los apus. Escritura andina en migración. Lima, Pakarina, 2012.

Nofal, Rossana. "Cuentos de guerra y soldados”. Moderna Språk, no. 106, 2012, pp. 127-135. Recuperado de http://ojs.ub.gu.se/ ojs/index.php/modernasprak/article/view/1186. 5 de enero de 2019.

"Escritura testimonial: cuentos de guerra y metáforas de la nueva narrativa argentina". Vertientes de la contemporaneidad. Géneros híbridos y nuevas subjetividades en la literatura latinoamericana. Elena Altuna y Betina Campuzano (Comps.). Salta, EUNSa, 2016, pp. 151-164.

"Configuraciones metafóricas en la narrativa argentina sobre memorias de dictadura". Kamchatka. Revista de Análisis Cultural, no. 6, 2015, pp. 835-852. Recuperado de https://ojs. uv.es/index.php/kamchatka/article/view/7603/7731. 12 de enero de 2019.

Polit Dueñas, Gabriela. "Cuando mirar no basta. Reflexiones sobre las crónicas de un mercado informal". Revista Canadiense de Estudios Hispánicos, vol. 38, no. 1, 2013, pp. 193-210.

Salazar Bondy, Sebastián. Lima la horrible. México: Era, 1964.

Sarlo, Beatriz. Tiempo pasado. Cultura de la memoria y giro subjetivo. Una discusión. Buenos Aires, Siglo XXI, 2007. 
Sklodowska, Elzbieta. Testimonio hispanoamericano. Historia, teoría, poética. Nueva York, Peter Lang, 1992.

Taylor, Diana. El archivo y el repertorio. La memoria cultural performática en las Américas. Santiago de Chile, Ediciones Universidad Alberto Hurtado, 2015.

Williams, Raymond. Marxismo y literatura. Trad. Guillermo David. Buenos Aires, Las Cuarenta, 2009. 